\title{
GEOTHERMAL ENERGY AND POWER GENERATION IN GERMANY
}

The EU is the world's largest energy importer, relying on imports for $50 \%$ of its energy needs. With an energy demand forecast likely to grow by 1-2\% a year, that figure will over the coming 20-30 years rise to $70 \%$.

The Geothermie is an inexhaustible energy source. With the supplies, which are stored in our planet, in principle the world-wide power requirement could be covered. The Geothermie, or terrestrial heat, is the warmth stored in the upper (accessible) part of the earth's crust. It covers the energy, as far as it can be extracted and used, stored in the earth, and ranks among the regenerative energies. It can be used both directly, approximately for heating and cooling in the heating market, and for the production by electric current or in a force heat coupling.

Production of heat using geothermal energy can be obtained in two very distinct ways. The first consists of directly exploiting subterranean water tables whose temperatures are included between $30{ }^{\circ} \mathrm{C}$ and $150{ }^{\circ} \mathrm{C}$ (so-called medium and low temperature applications). The second makes use of geothermal heat pumps that come under the heading of so-called very low temperature applications.

\section{Introduction}

The EU is the world's largest energy importer, relying on imports for $50 \%$ of its energy needs. With an energy demand forecast likely to grow 1-2\% a year, this figure will rise within the coming 20-30 years up to $70 \%$. Yet Europe's energy needs are growing relatively slow in comparison to other parts of the world. Therefore it has to compete increasingly for energy resources. Climate change has also put renewable energy on the agenda and Europe is investing in renewable energy sources.

The total installed capacity of worldwide geothermal power plant from 1975 up to end of 2007 (estimated) is given in Table 1.

Installed capacity from worldwide

Table 1 geothermal power plant

\begin{tabular}{|c|c|}
\hline Year & Installed Capacity (MWe) \\
\hline 1975 & 1300 \\
\hline 1980 & 3887 \\
\hline 1985 & 4764 \\
\hline 1990 & 5832 \\
\hline 1995 & 6833 \\
\hline 2000 & 7972 \\
\hline 2005 & 8933 \\
\hline 2007 & 9732 \\
\hline 2010 & 10993 \\
\hline
\end{tabular}

Binary plant technology is playing a very important role at the modern geothermal electricity market. The economics of electricity production are influenced by the drilling costs and resource development (typical quota is $30 \%$ for reservoir and $70 \%$ plant); the productivity of electricity per well is a function of reservoir fluid thermodynamic characteristics (phase and temperature), and the higher the energy content of the reservoir fluid, the lesser is the number of required wells.

Geothermal Energy provides approximately $0.4 \%$ of the world's global power generation, with a long term stable growth rate of $5 \%$. At present the largest markets are in the USA, the Philippines, Mexico, Indonesia, Italy and Iceland [1].

Table 2 Largest markets for geothermal power generation. We see that Germany is far behind this capacity due to different geo-

Largest markets for geothermal power generation Table 2

\begin{tabular}{|c|c|}
\hline Country & Installed Capacity (MWe) \\
\hline USA & 2690 \\
\hline PHILIPPINES & 1970 \\
\hline INDONESIA & 970 \\
\hline MEXICO & 950 \\
\hline ITALY & 810 \\
\hline ICELAND & 420 \\
\hline GERMANY & 8.9 \\
\hline
\end{tabular}

\footnotetext{
* Gerhard Braunmiller ${ }^{1}$, Peter Horbaj ${ }^{2}$, Natalia Jasminska ${ }^{2}$

${ }^{1}$ Miesbach, Germany, E-mail: g.braunmiller@eb-ing.com

${ }^{2}$ Faculty of Mechanical Engineering, Technical University of Kosice, Slovakia
} 
logical circumstances. Future developments are limited to certain areas worldwide, particularly under current technologies. Research and Development is required to develop potential for the other areas [2].

\section{Present Technology for geothermal electricity generation}

For generating electricity a direct usage of steam would seem to bet he thing to do with hydrothermal heat - and dry steam deposit with temperatures over $150{ }^{\circ} \mathrm{C}$. One of the first plants in this field wwas put into operation in Italy at the beginning of the last century. Experience in commercial operations has been gained worldwide for approximately 40 years. If the enthalpy content of thermal water is too low for fluid to relax directly in the turbine, systems with secondary cycles will be used. The soil heat will be transferred via one or several heat exchanger into a closed power station process. Such systems are also used if the thermal fluid has an extraordinary high quantity of non-condensable gases construction and operation of the turbine would require technically complex solutions that are even more costly than the usage of secondary fluids or if the thermal fluid is very aggressive, i.e. strong mineralisation or high quantity of hydrogen sulphide. The heat source is cooled down noticabley during the heat transmission to the secondary cycle. Whereas the water depression will probably undergo only a small temperature increase during heat transmission from the power station processs [3].

\section{Technology Systems for low enthalpie power generation}

In principal, two systems are available for the low enthalpy power generation. Since the 1930s the Organic Rankine Cycle (ORC) has been used in different geothermal power stations. In the 70s, Alexander Kalina developed a new heat exchange technique to produce vapor at a low temperature level. In the so called Kalina cycle a mixture of ammonia and water is used to generate a vapor cycle at low level temperatures around $100{ }^{\circ} \mathrm{C}$ as a power source for turbines. It is expected to gain an increase of efficiency with this binary system in comparison to the ORC cycle that may be up to $25 \%$. The reason for this supposition is the boiling of binary ammonia - water mixture at a variable temperature unlike pure water or other fluids which boil at a constant temperature. Variable temperature of boiling permits the working fluid to maintain a temperature closer to that of hot combustion gases in the boiler, thus, improving the exergy efficiency, a fact which has been well known among engineers. The first European geothermal power plant with Kalina technology with 2 [MWel] () was installed in 2002 in Husavik, Iceland [1].

\subsection{ORC-Process}

Fig. 1 ORC-Process (Organic - Rankine - Cycle) shows a schematic structure of the simple geothermal driven ORC.
Thermal water is brought out of the production well to the power station through a feed pump. There it sends heat through a vaporizator and preheater to the equipment before it is conducted back into the subsoil through the injection well. In the secondary cycle - the ORC - the equipment is running through the preheater and vaporizator after a pressure increase by the feeding pump. The steam relaxes within the turbines. Organic - Rankine - Cycle has () been installed and operated for more than 20 years worldwide. The turbine power can reach from a few hundred $\mathrm{kW}$ up to more than five MW. In Germany, only few plants of this type are () operating. One of them is the geothermal driven power station in Neustadt-Glewe, Mecklenburg - Vorpommern that was first put into service in November 2003 [1 and 6].

\subsection{Kalina-Process}

In principle, the Kalina cycle (Fig. 2) corresponds to a Clausisus - Rankine - Process with a high degree of internal heat recovery as well as additional destilation units. The union of the internal heat transmitter and the addition or reduction of destilation units allows good adjustment to a wider temperature range of possible heat sources. One of these systems was realised in Husavik, Island. This system is described in [4].

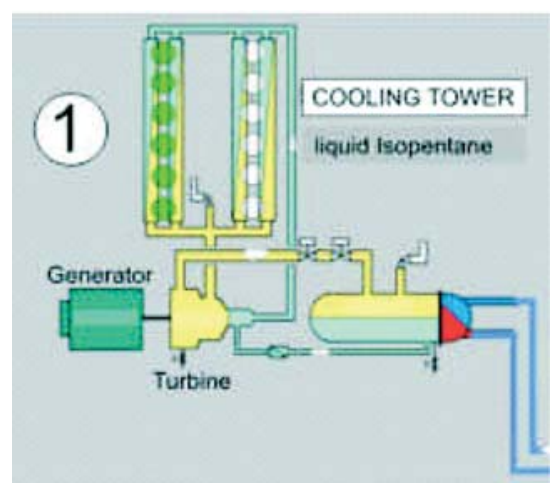

Fig. 1 ORC - Process

The geothermal heat is transferred to the main dissolving that is preheated in high temperature (High Temperature, HT-Rec()uperator) and low temperature heat recovery (Low Temperature, LTRec()uperator). Ammonia - rich steam and ammonia - poor dissolving are divided in a sepearator. The ammonia - poor dissolving is transferred directly to the HT-Rec()uperator where it heats the main dissolving. The steam relaxes within the turbine and drives the generator. Afterwards both substances are united again in the mixer.

\subsection{Pros and cons of the process}

()Comparing() both processes for thermal water temperatures from $100{ }^{\circ} \mathrm{C}$ to $200{ }^{\circ} \mathrm{C}$ and considering air cooling and fresh water cooling it can be said that Kalina plants are superior in the 


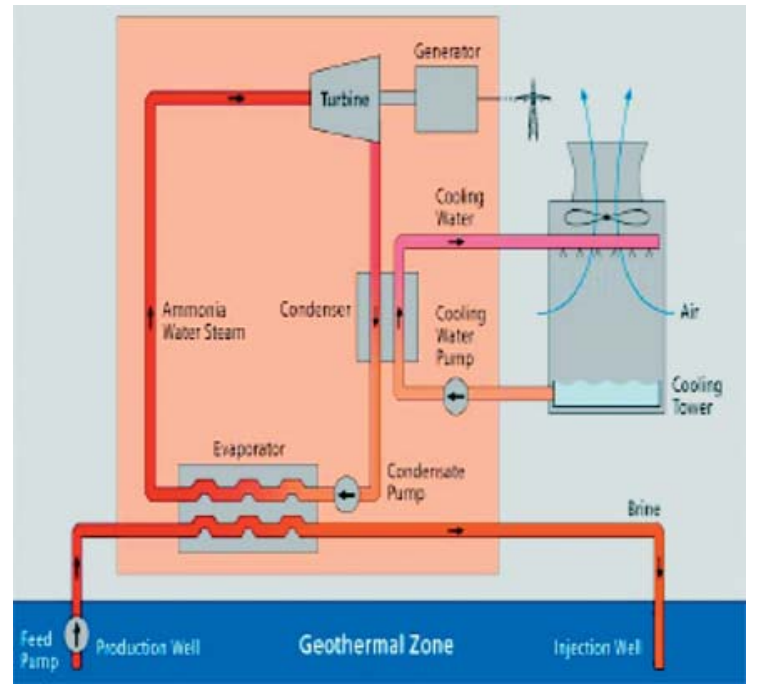

Fig. 2 Kalina-Process

lower temperature range, especially with air cooling, whereas ORC plants reach higher mains within the higher temperature range. Kalina plants do not extract () as much heat from thermal water as ORC plants do, but they convert this heat with a much higher thermal effectivenesss into electric energy. In contrast to ORC plants, with Kalina plants the point of maximum efficiency changes with the temperature increase of the heat source to a higher return temperature of thermal water [5].

Consequently, with thermal water temperature of $150{ }^{\circ} \mathrm{C}$, the effectiveness of cooling is a lot lower in Kalina plants than it is in ORC plants. Remedy could be found by modifying the process. On the other hand, it is the little cooling that makes further usage of thermal water possible. It can be used for combined heat and power stations [7].

Contrastingly, ORC plants suffer from this low thermal effectiveness that leads to high energy needs for the process, especially with cooling. Estimated cost of investments depends on temperature and velocity of flow of geothermal medium, first of all [8].

\section{Summary}

For geothermal electricity production, the highest concentration of resource on the European continent is located in Italy, Iceland and Turkey; the present exploited value is only $0.3 \%$ of the whole renewable market. The possibilities for geothermal energy to expand its penetration in Europe is mainly from the Enhanced Geothermal System (EGS); whereas the drilling technology is already in a mature stage, and efforts can only be done to reduce the drilling costs. The stimulation technologies are still in the pilot stage [9].

There are many geothermal prospects with high temperature, but they either lack fluid in the formation or the rock permeability is too low for permitting fluid circulation. These systems can be enhanced by engineering the reservoir through stimulation activities: acidizing and hydraulic fracturing. Due to the development of these technologies a huge geothermal potential will be available.

We should consider the new binary plants of Austria and Germany, proving the possibility of producing some geothermal electricity also from low temperature resources as very good and positive signals.

The present worldwide installed capacity of 9.7 GWel will increase up to $11 \mathrm{GWel}$ in 2010 . It has medium investment costs, depending on resource quality (temperature, fluid chemistry and thermodynamics phase, well productivity,...), ranging approximately from 2 to $4.5 / \mathrm{MW}$, and with very attractive generation costs, from 40 to $100 / \mathrm{MWh}$. It is a resource suitable for base load power. It can be considered as broadly cost-competitive, despite its relatively high capital costs for the development of the geothermal field (resource evaluation, mining risk, drilling and piping) for its very high availability and the stability of energy production. For the next generation it is expected to see the implementation of the Enhanced Geothermal System production and an intensive increase of low-to-medium temperature applications through binary cycle and cascade utilizations.

\section{References}

[1] RUGGERO, B.: World Geothermal Generation in 2007, Proc. of European Geothermal Congress, 2007.

[2] BUONASORTE, G. et al.: Geothermal Development in Italy: From Present to Future, Proc. of European Geothermal Congress, Unterhaching, Germany, 2007.

[3] KNAPEK, E., KITTL, G.: Unterhaching Power Plant and Overall System, Proc. of European Geothermal Congress, 2007.

[4] KALINA, A.: ASME Journal of Engineering for power, 4/1984.

[5] KOHLER, S.: Geothermisch Angetriebene Dampfkraft Prozesse, Dissertation, Fakultat III - Prozesswissenschafen der Technischen Universitat Berlin, 2005.

[6] PERNECKER, G.: Low enthalpy Power Generation with ORC - Turbogenerator, The Altheim Project, Upper Austria, GEO - Heat Center, Bulletin, 1/2003.

[7] RYBAR, P., RYBAR, R., TAUS, P.: Alternatively Power Sources (in Slovak), TU FBERG Kosice, 2001, p. 121.

[8] JANDACKA, J.; MALCHO, M.; MIKULIK, M.: Technologies for Development and Energy Exploitation of Biomass (in Slovak), ES ZU Zilina, 2007, p. 222.

[9] BRAUNMILlER, G., HORBAJ, P.: Comparison Germany-Slovakia Utilisation Geothermal Energy, Acta Mechanica Slovaca, 4D/2007, pp. 523-528. 